\title{
The effect of job resources and public service motivation on affective commitment: The mediating role of work engagement
}

\author{
D.H. Rajagukguk \& P.M. Desiana \\ Faculty of Economics and Business, Universitas Indonesia, Jakarta, Indonesia
}

\begin{abstract}
This paper aims to show the antecedents and consequences of work engagement (WE) in the government sector. Specifically, this paper examined whether public service motivation (PSM) and job resources (JR) are significantly related to work engagement in the context of the government sector. Furthermore, this paper examined whether WE mediates PSM and JR's relationship toward affective commitment (AC). This study used a cross-sectional survey research design. Data were collected from 162 employees who work in the government agency located in Jakarta, Indonesia. SEM-Lisrel was used as a tool in data analysis. In line with expectations, JR and PSM have a positive and significant impact on WE. Besides, WE also plays a role in mediating the relationship between JR and PSM to AC. This study shows JR and PSM's role in influencing employees' WE and AC in the government sector. This study is one of the few studies that provide an overview of JR and PSM's impact on WE and AC for employees in the Indonesian government sector.
\end{abstract}

\section{INTRODUCTION}

Referring to the three-component model (TCM) of organizational commitment, Allen and Meyer (1990) divided the types of organizational commitment into affective commitment, normative commitment (obligation-based), and continuance commitment (cost-based). The research found that affective commitment had the strongest positive correlation with job performance, organizational citizenship behavior, and attendance (Meyer, 2014; Mayer, Stanley, \& Parfyonova, 2012). Increasing the level of affective commitment is important for organizations during this pandemic time to maintain the performance of employees of the organization. The government organizations are faced with budget constraints and have limitations in allocating their expenditure in an effort to improve employee performance. In a meta-analysis study conducted by Fletcher, Bailey, Alfes, and Madden (2020), it was revealed that work engagement had a role in increasing employee commitment to the organization, especially affective commitment. Employees who experienced a high level of engagement are physically healthier, more satisfied with their psychological needs, and also get more benefits, including being more committed to the organization when compared to employees with low level of engagement (Borst, 2018). One concept that can explain the driving factors of work engagement is the job demands-resources (JD-R) framework (Lesener, Gusy, Jochmann \& Wolter, 2020). Job resources include support from superiors, autonomy, and performance feedback. They are intended as "good things" at work since they encouraged performance achievement and self-development as well as reduced the impact of psychological burdens that were considered to have the most positive impact on work engagement and affective commitment (Schaufeli, 2017; Dominguez, Chambel, \& Carvalho, 2020; Albrecht \& Marty, 2020). In the context of the public service sector, public service motivation is seen as a "major psychological resource" (Bakker, 2015), which is expected to encourage a high level of engagement (Lavigna, 2013). A research shows that a high level of public service motivation had a positive effect on public servants' level of engagement (Borst, Kruyen, \& Lako, 2019; Cooke, Brant, \& Woods, 2019; Gross, Thaler, \& Winter, 2019). Besides, based on research, it was also revealed that public 
service motivation positively and significantly affected affective commitment (Borst, Kruyen, \& Lako, 2019; Potipiroon \& Ford, 2017). Albrecht and Marty (2020) revealed that work engagement mediated the relationship between job resources and employees' affective commitment in a more general and diverse sector. Meanwhile, in the context of the public sector, Borst, Kruyen, and Lako (2019) concluded that engagement positively mediates the relationship between public service motivation and employees' affective commitment in the public sector.

\section{LITERATURE REVIEW}

Affective commitment is defined as a desire to remain as a member of an organization because of emotional attachment and involvement with that organization. Affective commitment is considered to have the strongest positive impact on the results achieved by the organization, and there have been a lot of research studies focusing on the relationship of results with the affective commitment (Meyer, 2014). Work engagement is a condition related to a positive psychological state, satisfaction, and motivation. Engaged employees had great energy, were enthusiastically involved in work, and had full concentration on work (Bakker, et.al., 2008). Schaufeli (2017) stated that every job has job demands and job resources. There are many types of "good things" in work that can be categorized as job resources. Several studies suggest that work autonomy, job feedback, and support from superiors have consistently affected work engagement and affective commitment (Schaufeli, 2017; Dominguez, Chambel, \& Carvalho, 2020; Albrecht \& Marty, 2020). Perry and Wise (1990) defined public service motivation as the tendency of individuals' motivation in public institutions and organizations. Perry (1996) identified four empirical components of public service motivation, such as attraction to public policy making, commitment to the public interest, compassion, and self-sacrifice.

\section{METHOD}

Based on literature reviews and previous research, the hypotheses developed in this study are as follows:

H1: Job resources have a positive effect on work engagement.

$\mathrm{H} 2$ : Job resources have a positive effect on affective commitment.

H3: Public service motivation has a positive effect on work engagement.

H4: Public service motivation has a positive effect on affective commitment.

H5: Work engagement has a positive effect on affective commitment.

H6: Work engagement mediates the relationship between job resources and affective commitment.

H7: Work engagement mediates the relationship between public service motivation and affective commitment.

This study used a non-probability sampling design. The type of sampling used was purposive sampling. The data were obtained by distributing self-administered questionnaires. The measurement used a 7-Likert scale from strongly disagree to strongly agree. The population in this study was 761 employees, and the samples were collected from 162 respondents. The primary data that had been collected were then analyzed using SPSS and Lisrel software.

\section{RESULTS AND DISCUSSION}

Based on this study's results, it was found that job resources had a positive and significant effect on work engagement, and thus, $\mathrm{H} 1$ can be accepted. This supports previous research conducted by Reina-Tamayo, Bakker, and Derks (2017), Dominguez, Chambel, and Carvalho (2020), and Albrecht and Marty (2020). Autonomy, supervisors' support, and feedback on the assigned work led 
to increase in work engagement of the employees. On the other hand, job resources had a positive but insignificant effect on affective commitment; hence, $\mathrm{H} 2$ cannot be accepted. This is different from research performed by Dominguez, Chambel, and Carvalho (2020) and Albrecht and Marty (2020). They stated that autonomy, supervisors' support, and feedback did not directly affect the employee's affective commitment, but the employee felt engaged with increase in organizational commitment. This finding is in line with the JD-R concept proposed by Schaufeli (2017), where job resources increased work engagement, and therefore, employees felt engaged. It was then proven that job resources have a positive impact on the organization, especially the commitment to the organization.

The following result reveals that public service motivation had a positive and significant relationship with work engagement; thus, $\mathrm{H} 3$ can be accepted. This finding supports previous research conducted by Borst (2018), Borst, Kruyen, and Lako (2019), and Cooke, Brant, and Woods (2019). Employees who had a high level of public service motivation were more engaged than employees who had a low level of public service motivation. Public service motivation is unique to the government sector. The fourth result denotes that public service motivation had a positive and significant relationship to affective commitment; hence, $\mathrm{H} 4$ can be accepted. This finding supports previous research carried out by Borst, Kruyen, and Lako (2019) and Potipiroon and Ford (2017). Therefore, during recruitment, government organizations need to measure public service motivation as one of the criteria. Besides, increased socialization within the organization regarding the importance of work for the community can increase public service motivation, employee work engagement, and affective commitment.

The fifth result indicates that work engagement had a positive and significant effect on affective commitment; thus, H5 can be accepted. Work engagement focuses on the relationship between employees and the work they do, while affective commitment emphasizes the relationship between employees and the organization they are a part of. Therefore, it can be concluded that the high level of work engagement felt by employees for their work increases emotional attachment, involvement, and self-identification within the organization (Schaufeli, 2017; Albrecht \& Marty, 2020). Finally, the last result signifies that work engagement mediated the relationship between job resources and public service motivation. The results are in line with a research conducted by Albrecht and Marty (2020) and Borst, Kruyen, and Lako (2019); thus, H6 and H7 can be accepted. It can be seen that work engagement has a significant role in driving positive outcomes for the organization. Therefore, organizations must conduct regular surveys of employee work engagement levels to find out how employees perceive job resources in the organization and the strategies needed to improve public service motivation in employees.

\section{CONCLUSION}

Providing autonomy, supervisors' support, and feedback to employees can create a positive and significant impact on work engagement, but it does not directly affect affective commitment. They only affect organizational commitment when their work engagement is taken into account. Public service motivation has a positive and significant relationship with work engagement and affective commitment. Therefore, during recruitment, government organizations need to measure public service motivation as one of the criteria. Besides, increasing socialization within the organization regarding the importance of work for the community can increase public service motivation, work engagement, and affective commitment. These results indicate that affective commitment is more influenced by personality characteristics rather than job resources. In contrast, work engagement is determined by personality characteristics and job resources. It confirms the idea that work engagement is more pervasive rather than affective commitment. All of the variables studied (i.e., autonomy, feedback, supervisors' support, and socialization) increase PSM and can be carried out during this pandemic without causing significant increase in expenditure for the employees. It can increase work engagement and affective commitment, leading to the desired organizational outcomes. 


\section{REFERENCES}

Albrecht, S. L., \& Marty, A. (2020). Personality, self-efficacy and job resources and their associations with employee engagement, affective commitment and turnover intentions. The International Journal of Human Resource Management, 31(5), 657-681.

Allen, N. J., \& Meyer, J. P. (1990). The measurement and antecedents of affective, continuance, and normative commitment to the organization. Journal of Occupational Psychology, 63, 1-18.

Bakker, A. B. (2015). A job demands-resources approach to public service motivation. Public Administration Review, 75, 723-732.

Bakker, A. B., Schaufeli, W. B., Leiter, M. P., \& Taris, T. W. (2008). Work engagement: An emerging concept in occupational health psychology. Work \& Stress, 22, 187-200.

Borst, R. T. (2018). Comparing work engagement in people-changing and people-processing service providers: A mediation model with red tape, autonomy, dimensions of PSM, and performance. Public Personnel Management, 47(3), 287-313.

Borst, R. T., Kruyen, P. M., \& Lako, C. J. (2019). Exploring the job demands-resources model of work engagement in government: Bringing in a psychological perspective. Review of Public Personnel Administration, 39(3), 372-397.

Cooke, D. K., Brant, K. K., \& Woods, J. M. (2019) The role of public service motivation in employee work engagement: A test of the job demands-resources model. International Journal of Public Administration, 42:9, 765-775.

Dominguez, D., Chambel, M., \& Carvalho, V. (2020). Enhancing engagement through job resources: the moderating role of affective commitment. The Spanish Journal of Psychology, 23, 1-12.

Fletcher, L., Bailey, C., Alfes, K., \& Madden, A. (2020). Mind the context gap: a critical review of engagement within the public sector and an agenda for future research. The International Journal of Human Resource Management, 31(1), 6-46.

Gross, H. P., Thaler J., \& Winter, V. (2019). Integrating public service motivation in the job- demandsresources model: An empirical analysis to explain employees' performance, absenteeism, and presenteeism. International Public Management Journal, 22(1), 176-206.

Lesener, T., Gusy, B., Jochmann, A., \& Wolter, C. (2020). The drivers of work engagement: A meta-analytic review of longitudinal evidence. Work \& Stress, 34(3), 259-278.

Lavigna, R. J. (2013). Engaging Government Employees: Motivate And Inspire Your People To Achieve Superior Performance. New York: Amacom.

Meyer, J. P. (2014). Employee commitment, motivation, and engagement: exploring the links. In Gagne, M. (Eds.), The Oxford Handbook of Work Engagement, Motivation, and Self-Determination Theory (pp. 33-49). New York: Oxford University Press.

Meyer, J. P., Stanley, L. J., \& Parfyonova, N. M. (2012). Employee commitment in context: The nature and implications of commitment profiles. Journal of Vocational Behavior, 80, 225-245.

Perry, J. L. (1996). Measuring public service motivation: An assessment of construct reliability and validity. Journal of Public Administration Research and Theory, 6(1), 5-22.

Potipiroon, W., \& Ford, M. T. (2017). Does public service motivation always lead to organizational commitment? Examining the moderating roles of intrinsic motivation and ethical leadership. Public Personnel Management, 46(3), 211-238.

Reina-Tamayo, A. M., Bakker, A. B., \& Derks, D. (2017). Episodic demands, resources, and engagement: An experience-sampling study. Journal of Personnel Psychology, 16(3), 125-136.

Schaufeli, W. B. (2017). Applying the job demands-resources model: A 'how to' guide to measuring and tackling work engagement and burnout. Organizational Dynamics, 46(2), 120-132. 